\title{
El testimonio y su dimensión filosófica: producciones de sentido sobre las dictaduras militares del Cono Sur ${ }^{1}$
}

Testimony and its philosophical dimensión. Productions of meaning about the military dictatorships of the Souther Cone of Latin-America

\section{MARIELA CECilia Ávila}

FONDECYT. UnIVERSIDAD DE SANTIAGO DE CHILE· marielnauta@yahoo.com.ar

Doctora en Filosofía por la Universidad Paris 8 Saint-Denis de Francia y por la Pontificia Universidad Católica de Valparaíso de Chile. Profesora y Licenciada en Filosofía con Orientación Práctica por la Facultad de Filosofía y Letras de la Universidad Nacional de Cuyo, Mendoza, Argentina. Entre sus líneas de trabajo se destacan el Pensamiento Político Contemporáneo y la Filosofía Latinoamericana. Actualmente lleva a cabo su investigación Postdoctoral Fondecyt sobre los campos de concentración de las últimas dictaduras del Cono Sur.

Resumen:Este trabajo busca analizar el testimonio desde su dimensión filosófica a fin de vislumbrar los efectos de sentido que esta narración puede abrir en el ámbito de la comunidad. Este análisis mostrará el lugar del testigo, y el modo en que la narración testimonial puede dar paso a complejos procesos de subjetivación. En este contexto se reflexiona sobre la escritura testimonial surgida a partir de la experiencia concentracionaria en Latinoamérica y las posibilidades críticas y políticas que estas narraciones abren en el presente.

Palabras Clave: Testimonio, Filosofía, Dictadura Militar, Latinoamérica, Subjetividad.

\begin{abstract}
This paper analyzes the testimony and its philosophical dimension to show the effects of meaning that these stories can develop in community. This analysis shows the location of the witness, and the way that testimonial narrative can lead to complex processes of subjectivation. In this context we examine the testimonial writing arisen from the concentration experience in Latin America and the critical and political possibilities that these narratives provides to the present.
\end{abstract}

Key Word: Testimony, Philosophy, Military Dictatorship, Latin America, Subjectivity.

\footnotetext{
${ }^{1}$ Este trabajo forma parte del Proyecto Postdoctoral FONDECYT $\mathrm{N}^{\circ} 3140089$ Análisis filosófico de los campos de prisioneros del Cono Sur a partir de los aportes de Hannah Arendt y Giorgio Agamben, y del Proyecto FONDECYT Regular N 1140200 Campos de prisioneros en Chile. Reconfiguración de los lugares y las subjetividades"
} 


\section{A modo de introducción: lo que busco, lo que no busco y lo que encuentro en el testimonio}

Valgan estas palabras como una introducción a este texto, que desde la filosofía, busca abrirse a los confines de la literatura y de la historia, tratando de demostrar que las distancias disciplinares no son necesariamente tales, y que las fronteras constituidas que las dividen tienen zonas grises, zonas de diálogo, en las que es posible cultivar reflexiones.

De esta manera, asumo mi lugar de enunciación como un lugar poroso, mixturado, e incluso intempestivo, que busca alejarse de una tradición que ha marginado el quehacer filosófico a una reflexión meramente especulativa. La tarea que emprendo aquí, tiene claros antecedentes en análisis que podríamos caracterizar como inmanentes, o siguiendo la rica tradición de pensamiento latinoamericano, como situados.

Sin respetar el orden expresado en el título de este primer apartado, comenzaré indicando que es lo que no busco en el testimonio, lo que probablemente me aleja de una tradición que anhela arribar a una verdad universal. En efecto, lo que yo no busco en el testimonio es una verdad en sentido ontológico o histórico, porque no creo que allí anide la riqueza de estas narraciones, o que sea la finalidad principal del testigo el enunciarla. A mis fines investigativos cobra mayor rendimiento un acercamiento a lo que Foucault ha dado en llamar una verdad-rayo, a la que caracteriza como una verdad discontinua que tiene la forma del acontecimiento.

De este modo, en mi trabajo con el uso, y quizá el abuso de testimonios de las últimas dictaduras del Cono Sur latinoamericano, lo que sí busco es vislumbrar la constitución de ciertos procesos y efectos actuales y de ciertas formas de subjetivación a partir de la palabra de los testigos. Apoyándome en la reflexión de Walter Benjamin, busco también evidenciar el valor del testimonio en tanto deconstructor de una historia lineal y oficial, para poder pensarla desde una mirada genealógica como una "historia a contrapelo".

Este uso del testimonio me deja en la posición de testigo del testigo, dónde, finalmente, encuentro que variadas formas discursivas me permiten asomar a diversos sucesos que no me pertenecen experiencialmente, pero que tomo para poder, en palabras de Hannah Arendt, comprender el presente, a fin de habitarlo, actuarlo, y sobre todo, hacerlo un poco más mío.

Dado lo anterior, iniciaré este recorrido mostrando una posible relación entre la filosofía y el testimonio, sobre todo a partir de la categoría de experiencia. Es por ello que analizaré la figura de la memoria en base a una ampliación metodológica, ya que busco vislumbrarla a partir de su dimensión colectiva. Es precisamente dicha ampliación, y su relación con la historia, la que me permitirá fijar la mirada en el o los sujetos que encarnan y ponen en acto esas memorias, que a su vez son los que se constituyen mediante la narración. 
Así, busco analizar el testimonio como un espacio de subjetivación, en el que sería posible evidenciar el lugar de aparición de ciertos "quienes" que a partir de la palabra, ponen su cuerpo en el espacio público y en la historia, convirtiéndose en testigos de lo sido. De este modo, a partir del análisis de estas voces narrativas busco vislumbrar la figura del testigo como un individuo que se re-subjetiviza a partir de su palabra, a la vez que pone de manifiesto el reciente pasado traumático en el ámbito de la comunidad brindando nuevas perspectivas reflexivas.

Desde este modo, llevaré a cabo una reflexión situada sobre la figura del testigo, centrándola principalmente en los campos de concentración del Cono Sur latinoamericano, lo que espero, permitirá vislumbrar los efectos de sentido que estas narraciones tienen sobre nuestro presente tanto a nivel singular, como a nivel colectivo.

Aclaro en este punto que esta investigación no busca arribar a conclusiones cerradas y finales, sino que considero este escrito como la posibilidad de pensar desde la filosofía sobre ciertos sucesos histórico-políticos afincados en el terror, que más que clausuras, demandan una reflexión situada, crítica y continua.

\section{Testimonio y filosofía, una posible relación}

Al momento de elegir trabajar con testimonios desde una perspectiva filosófica, se me presentan algunos interrogantes que dicen relación con el lugar asignado al género testimonial y a su validez en el quehacer disciplinar. Desde cierta tradición, pareciera ser que la palabra personal y subjetiva no puede alcanzar el grado de reflexión filosófica, y esto debido a la singularidad que dicha narración enuncia. En efecto, la tradición filosófica ha tenido mucho cuidado en no aunar el ámbito subjetivo con el llamado universal, relegando de esta manera la inmanencia y sus avatares al campo de la historia, la literatura, la psicología, la sociología, o el arte, entre otras disciplinas.

No obstante, en la reflexión desarrollada en el ámbito del pensamiento latinoamericano, encontramos una notable ampliación de la noción de escrito filosófico a otras formas discursivas. En efecto, desde la Historia de las Ideas se vislumbran ricos análisis que dan cuenta de la manera en que el pensamiento filosófico se amplía a diversos modos de expresión y acción. En este contexto, el punto central no es la forma del discurso, o no sólo eso, sino el modo en que dicha forma se despliega y los posibles efectos prácticos que desencadena. De este modo, entran en escena otras maneras de ejercer la discursividad, que a partir de los efectos que generan son claras portadoras de reflexión filosófica. Es entre estas formas que sitúo al testimonio.

Desde esta perspectiva, y dado lo anterior, considero que no sería tan complejo vislumbrar una relación existente entre filosofía y testimonio, ya que a partir de la palabra enunciada por un sujeto singular, en la que expresa su experiencia a partir de un suceso, sería posible generar una reflexión con 
espesor filosófico, que permita alcanzar un mayor grado de comprensión de ciertos acontecimientos y situaciones.

Considero además, que el testimonio en tanto narración de la experiencia viva, activa el pensar, y en este sentido, muestra otros mundos posibles que permiten poner en jaque ciertos discursos instaurados con pretensión de verdad. En esta línea, acuerdo con Hannah Arendt cuándo indica que: (...) el acto más pequeño en las circunstancias más limitadas lleva la simiente de la misma ilimitación, ya que un acto, y a veces una palabra, basta para cambiar cualquier constelación" (Arendt, 2008: 214).

Ahora bien, y asentándome en la estructura del testimonio, creo que es posible observar un nexo cuasi constitutivo entre esta forma de narración, la memoria y la historia. Si bien no ahondaré sobre la compleja y amplia relación entre estos tópicos en el presente trabajo, sí me interesa mostrar que esta amalgama, sobre todo a partir de la reflexión de Maurice Halbwachs en La memoria colectiva (2011), adquiere dimensiones políticas. En efecto, es Halbwachs quien retomando los postulados que presenta el filósofo Henry Bergson en Materia y Memoria -texto de 1896- renueva la reflexión sobre la memoria al pensarla desde un ámbito relativo a lo plural. Así, Halbwachs, tomando como punto de partida la reflexión bergsoniana, pero percibida desde la lente durkheimiana, promulga una memoria asentada en lo colectivo. La posibilidad de pensar la memoria como una construcción no sólo individual sino también colectiva, arroja una nueva mirada a la historia -expresada en la relación entre el presente y el pasado-, y sobre todo, a los modos en se reconstruye y narra lo acontecido.

Ahora bien, aún reconociendo que sería muy interesante reflexionar sobre la posible relación entre Bergson y Benjamin -sobre todo a partir de la noción de duración- profundizaré casi exclusivamente en la posibilidad de construcción de una memoria de carácter colectivo en el trabajo del filósofo berlinés. En efecto, mi intención en este escrito es la de abordar el trabajo de Benjamin apostando a la idea de que la memoria, e incluso la historia, en su obra presentan la marca de lo colectivo². Así, la memoria, o mejor la remembranza o recordación, sería para Benjamin el factor que posibilitaría que los vencidos no caigan en un olvido sin fin, tanto histórico como material. Y es precisamente esa recordación, la que creo, no sería sólo parte de una conciencia singular, sino que la rebasaría, asentándose en la necesidad de memoria y justicia colectiva. En este punto creo importante remarcar que, tal como indica Reyes Mate, el escrito sobre las tesis de la historia no busca repensar sólo la memoria, sino la totalidad de la historia, y esto a partir de la singularidad de los sucesos que están, precisamente, en la memoria:

\footnotetext{
${ }^{2}$ Esto no significa que esta suerte de memoria colectiva que podríamos leer en estas tesis benjaminianas se sitúen en un carácter encuadrante. Por el contrario, la constante reconstrucción de un pasado injusto en el presente, y el trabajo que desarrolla Benjamin a partir de los restos, los andrajos y lo marginal, rompen con toda posibilidad de encuadre de lo sido, pues precisamente, lo que se busca es quebrar los marcos de unificación temporal e histórica. Para profundizar el análisis y la crítica a la noción de encuadre en Halbwachs véase el trabajo de Pollak Michel (2006). Memoria, olvido, silencio. La producción social de identidades frente a situaciones límite. La Plata: Al Margen.
} 
Mariela Cecilia Ávila. La dimensión filosófica del testimonio...

La teoría del conocimiento de Benjamin saca el pasado frustrado de ese sopor al descubrir vida en esas muertes. Los proyectos frustrados de los que quedaron aplastados por la historia están vivos en su fracaso como posibilidad o como exigencia de justicia (Reyes Mate, 2009: 21).

Benjamin muestra entonces la fragilidad de un presente que se piensa a partir de un desarrollo causal, lineal y consecuente de la historia, organizado exclusivamente en torno a la experiencia de los vencedores, dejando de lado el testimonio sepultado por el polvo de aquellas vidas sufrientes, superadas por el desarrollo y expulsadas de la historia "universal". Estas narraciones unilaterales, reconocidas como verdades establecidas, expulsan la posibilidad de otras experiencias, entronando la idea de una universalidad unívoca amparada en el progreso y en la ilusión de una historia sin fisuras. Esta historia que según Benjamin cuentan los vencedores, es una historia que deja de lado el testimonio de los vencidos, arrojados a la vera del devenir histórico mismo.

La tarea a la que se aboca Benjamin entonces, es la de rescatar a partir de la multiplicidad de la experiencia las voces de aquellos sujetos oprimidos, pues como indica Reyes Mate, "el sujeto en el que él piensa no es un sujeto anestesiado, sino alguien que asume conscientemente su experiencia del sufrimiento y lucha contra sus causas" (2009: 20).

Ahora bien, Benjamin -a quién sitúo cercano a Nietzsche en este punto- piensa la historia de un modo intempestivo, podríamos decir, fijándose en las rupturas y oscuridades de un acontecer siempre en conflicto. Al centrarse en los trapos y en los deshechos que el progreso ha dejado tras de sí, Benjamin no busca reflexionar sobre una narración histórica que justifique el presente, sino por el contrario, arremete contra ese relato con un carácter desestabilizador, para mostrar que el presente es mucho más que lo que aparenta, y que sus orígenes son espurios y oscuros. De allí que considere que todo documento de cultura, es a la vez, un documento de barbarie, que carga sobre sus heridas espaldas la posibilidad del progreso de los hombres. Su visión de la historia, y de la filosofía en general, se aleja de un universal totalizante, que dé cuenta del mundo y de la existencia, pues considera esta percepción unificadora plena de violencia, ya que expulsa lo singular no sólo del concepto, sino también de la vida y de la cultura. Así, en su VII tesis Benjamin indica:

(...) Todos los que hasta aquí obtuvieron la victoria participan de ese cortejo triunfal en el que los amos de hoy marchan sobre los cuerpos de los vencidos de hoy. A ese cortejo triunfal como fue siempre la costumbre, pertenece también el botín. Lo que se define como bienes culturales. (...) No hay ningún documento de cultura que no sea a la vez un documento de barbarie. Y la misma barbarie que los afecta, afecta igualmente el proceso de su transmisión de mano en mano. Por eso, el teórico del materialismo histórico se aparta de ellos tanto como le sea posible. Su tarea, cree, es cepillar la historia a contrapelo (Löwy, 2012: 81).

En este punto me interesa centrarme especialmente en la versión francesa de esta tesis, traducida a tal idioma por el mismo Benjamin. En efecto, en el texto en francés, en la parte final de la tesis, encontramos las palabras témoigne y témoigner: “(...) Tout cela ne témoigne pas de la culture sans 
témoigner, en même temps, de la barbarie" (Reyes Mate, 2009, 131). Sin embargo, tanto Manuel Reyes Mate, como Michael Löwy y Pablo Oyarzún, cuyos trabajos he consultado para este escrito, parecen haber traducido al castellano directamente del alemán este párrafo, dónde no se encuentra alusión alguna al testimonio. En esta línea, indico que el verbo Témoigner en francés alude a mostrar, demostrar, ser prueba de algo, pero también, y sobre todo, a testificar y testimoniar.

Me parece interesante remarcar esto, pues la idea de que sea la cultura misma la que da testimonio de su corazón bárbaro, permitiría pensar el estatuto del acto de testimoniar como inscrito al interior de los sucesos mismos. Es decir, la cultura lleva en sí y otorga, aún sin quererlo, el testimonio de sus orígenes salvajes y violentos, y por este acto mismo, sería imposible ya olvidar u ocultar el piso sufriente sobre el que ella y sus producciones se han fundado.

Creo que la apuesta benjaminiana de cepillar la historia a contrapelo tiene que ver, precisamente, con la posibilidad de iluminar y dar voz a aquellos testimonios que demuestran que el pasado, la cultura y la historia no se han construido sobre la base de un devenir sin tropiezos, sino que por el contrario, ocultan sufrimiento, cuerpos rotos, y proyectos frustrados. Sin ahondar en el ámbito del mesianismo, podríamos decir que Benjamin busca rescatar aquellos sujetos de experiencia que fueron arrojados a los márgenes, para darles en la historia el lugar de una materia necesaria e insoslayable, que clama por justicia y memoria, incluso más allá del tiempo presente.

Es en este sentido y en esta línea, dónde me atrevo a vislumbrar una fecunda relación entre la filosofía y el testimonio, pensando este último como un instrumento crítico y colectivo, propicio para horadar ciertas prácticas y discursos en apariencia, sólo en apariencia, vencedores y perpetuos.

\section{Testimonio y subjetividad: develar un quién en la historia}

Así, y partir de lo expresado en el apartado anterior, busco pensar los testimonios de las últimas dictaduras del Cono Sur como narraciones experienciales, que permitirían sacar a la luz de la comunidad ciertas existencias que expresan vivencias del horror y la catástrofe. Me interesa entonces, abordar de modo filosófico la singularización que enuncian los testimonios en tanto procesos de subjetivación, a partir de los que se podría constituir un relato que tiene como punto de inicio la experiencia.

Ahora bien, en no pocas ocasiones se me ha reprochado, desde una perspectiva metodológica, el uso de testimonios para reflexionar filosóficamente. En efecto, las posturas más ortodoxas dejan fuera de la filosofía la experiencia, y ante esto, yo me sitúo en la vereda contraria, pues creo junto a Hannah Arendt, que la experiencia proveniente de realidad es la que activa el pensar. Según Arendt, la realidad es la que da que pensar, y la que en última instancia, nos permite desarrollar un ejercicio de comprensión sobre los sucesos. Y en este ámbito, creo que el testimonio en tanto narración de experiencia, nos acercaría al proceso de comprensión arendtiano, que incluye novedad, pero también memoria. 
En esta línea es interesante notar cómo a partir de la narración testimonial el acto se recrea cada vez que se enuncia, pero siempre matizado por la experiencia del presente y su fusión con la memoria de lo acontecido. La memoria dice relación con el presente, pues a partir de un "ahora" que reconstruye el pasado es posible quebrar el continnum de la historia, aún cuando los protagonistas de los sucesos que se narran no se encuentren presentes ya. En esta línea y pensado en la reflexión de Horkheimer sobre la memoria y el recuerdo, Reyes Mate indica:

La memoria permite mantener viva y vigente la injusticia pasada hasta el punto de que sin esa recordación el pasado deja de ser y la injusticia se disuelve. Este poder de la memoria -y esta precariedad de la ética- es de tal magnitud que debería ser añade [Horkheimer] el interrogante de la filosofía (Reyes Mate, 2009: 26).

Este interrogante de la filosofía tiene, según Horkheimer, como punto de partida la memoria del pasado, la recordación de ciertos sucesos injustos que ella mantiene vivos en el presente. Si bien acuerdo con estas ideas, considero que la reflexión puede complejizarse al abrirla a un campo más amplio, y esto a partir de la incorporación de la dimensión de la subjetividad. En efecto, en la narración testimonial que se desprende de la memoria, no sólo se hace patente el suceso injusto por el que se lucha para que no caiga en el olvido, sino que también aparece en escena el sujeto que encarna dicha narración.

En este punto dónde nos acercamos a Arendt y a su escrito Ensayos de comprensión ${ }^{3}$, para mostrar el lugar que ocupa el testimonio en tanto revelador de un quépero también de un quién. Aquí aparece un sujeto, que en tanto narrador de sucesos singulares, coloca su voz y su cuerpo en la historia. Considero entonces, que la palabra singular presente en los testimonios tiene claros efectos políticos, ya que va en la línea de construir un análisis de espesura filosófica que permita vislumbrar el presente como un campo nunca clausurado y abierto a infinitas posibilidades, a fin de reflexionar y actuar en el espacio público.

Para Arendt palabra y acción se constituyen en una unidad indisoluble, pues son los elementos que brindan a los hombres su condición humana y en tanto tal, son los que permiten el verdadero ejercicio político. Estos dos elementos -discurso y acción-, más allá de estar indisolublemente unidos entre sí, lo están también al nacimiento. La natalidad es uno de los conceptos clave en el pensamiento arendtiano, pues es a partir de la aparición de cada nuevo sujeto en la historia que es posible pensar, precisamente, la novedad: un nuevo comienzo y una reinterpretación de las palabras y discursos que están dados

\footnotetext{
${ }^{3}$ El título original de este artículo es Understanding and Politics (The Difficulties of Understanding) y fue publicado en el N ${ }^{\circ}$ 20 de Partisan Review en el año 1953. En este caso hacemos uso de la traducción de Cristina Sánchez Muñoz.
} 
previamente en el mundo. Mediante la narración, expresada en stories $^{4}$, que son pequeños relatos que se incorporan en la historia o history, lo que aparece es un sujeto narrador, un "quién”, que cuenta una existencia. En este sentido, Arendt indica:

Acción y discurso están tan estrechamente relacionados debido a que el acto primordial y específicamente humano debe contener al mismo tiempo la respuesta a la pregunta planteada a todo recién llegado “¿Quién eres tú?”. Este descubrimiento de quien es alguien está implícito tanto en sus palabras como en sus actos; (...) (Arendt, 1998: 202).

\section{El lugar del testimonio. La voz del testigo}

Ahora bien, a partir de lo dicho surgen algunos interrogantes que oficiarán de guía en este apartado. Nos preguntamos entonces, ¿qué rendimiento filosófico, pero también político, tendría pensar a partir de narraciones singulares que muestran un "quién” en la historia?, ¿podría la subjetividad expresada en testimonios tener efectos perceptibles en órdenes discursivos y prácticos?, ¿puede la narración de la tortura y del encierro abrir la reflexión a otros ámbitos y actores no involucrados directamente en los sucesos que expresa?, y finalmente, ¿es posible pensar procesos de subjetivación a partir de testimonios?

Para intentar dar respuesta a estos interrogantes, partiremos de la consideración del testimonio como una expresión subjetiva, es decir, como una materialización en la narración de la experiencia de un sujeto sobre un suceso. Ahora bien, esta narración subjetiva no deja de lado la posibilidad de la construcción plural del testimonio. En efecto, considero posible la organización y enunciación del testimonio a partir de voces y memorias múltiples, que contribuyen en la constitución y expresión de una narración ${ }^{5}$. En este sentido, la narración testimonial se nutriría de diversas voces y de amalgamas de

\footnotetext{
${ }^{4}$ Arendt evidencia una distinción terminológica que existe en la lengua inglesa para referirse a la historia. En efecto, en esta lengua al igual que en el alemán o el italiano, la historia se aborda desde dos dimensiones: con el término history se alude a los acontecimientos, mientras que con story se hace referencia a las narraciones que se erigen sobre dichos sucesos. Tanto la lengua española como la francesa carecen de esta distinción. Un interesante análisis sobre este tópico ha sido desarrollado por el historiador François Dosse (2003).

${ }^{5}$ Considero iluminador en este sentido pensar la crítica que Stoll hace a Rigoberta Menchú luego de un minucioso trabajo de investigación sobre el espacio y el tiempo de los sucesos. Stoll busca invalidar el testimonio de Menchú al aludir que ella no estuvo presente, tal como indica, en la matanza en la que es asesinado su hermano. Menchú acepta esta situación, pero dice que las narraciones y vivencias de aquellos que sí estuvieron presentes le fueron transmitidas, lo que permitió la escritura de su testimonio. En este punto destaco la posibilidad de construcción colectiva que tiene el testimonio, puesto que muestra con claridad los sentidos y efectos que su enunciación provoca en el ámbito de la comunidad. Para profundizar la crítica de Stoll a Menchú, remitirse a Beverley (2012).
} 
memorias, que dan la posibilidad de abarcar los sucesos desde una mirada más amplia, enriqueciendo su producción y sus sentidos ${ }^{6}$.

Esto sitúa a quienes son receptores y trabajan con testimonios en un lugar cercano a la figura que he dado en llamar testigos del testigo, pues la percepción que se tenga de los acontecimientos descritos se encuentra siempre mediada por la vivencia del narrador. Es decir, el acceso al suceso no es directo, sino que es el narrador quien ha tenido la experiencia y la ha plasmado en una story. Por otro lado, la narración testimonial es quizá el único modo de conocer estos sucesos, lo que de alguna manera nos hace partícipes de los mismos, pues nada sería del testimonio si no tuviese lectores a los que transmitir sus palabras y memorias. De modo redundante se puede decir que el testimonio busca testigos de su testificación, lo que evitará el olvido de lo que ha sucedido.

En este punto remarco que la figura de testigo del testigo en ningún caso se acerca a la de testigo vicario, que sería la de aquel sujeto que narra experiencias sin tener relación directa con los hechos, es decir, que habla en nombre de otros, ya sea porque los acontecimientos le han sido transmitidos o por considerarse apto para hablar por los demás. La figura del testigo vicario alude a quien por empatía o identificación, pretende narrar y testificar sobre sucesos que no guardan relación directa con su propia experiencia. Esta vicarización del testimonio queda en evidencia al considerar que la narración se encuentra siempre mediada por la experiencia del re-narrador, pues hay un otro que se cuela en las vivencias sin tener ningún tipo de relación con ellas y las relata como propias. En todo caso, no es mi intención llevar a cabo una crítica sobre este modo de testimonio, no obstante esta dimensión tanto del testigo como del testimonio no resulta fructífera a los fines de mi reflexión. Pues por el contrario, busco testimonios -singulares o colectivos-, que den cuenta de vivencias experienciadas podríamos decir, instaurando tal vez un neologismo.

Por su parte, el papel del testigo del testigo -lugar en el que me sitúo-, me mantiene en la línea del espectador y no en la de narrador directo del suceso, pues serán las palabras de ese otro que ha experimentado el acontecimiento, las que iluminen la reflexión y produzcan ciertos efectos. La narración pertenece a la experiencia del testimoniante, sin embargo, sus palabras producen ciertos efectos que no son menores, pues el uso de testimonios en el análisis actúa como un dispensador que otorga diversos sentidos para pensar el presente.

En este punto es interesante vislumbrar lo que Fina Birulés siguiendo a Beatriz Sarlo, llama una rehabilitación del yo para hacer referencia a la creciente valorización del sujeto moderno en la actualidad

\footnotetext{
${ }^{6}$ En este punto aludo a la posibilidad de escribir testimonios de modo colectivo, como en el caso del texto Ese infierno que es fruto del diálogo de cinco mujeres, presas políticas durante la última dictadura militar argentina en la Escuela de Mecánica de la Armada: Actis, Munú, Aldini, Cristina, y Otras (2001). Otro caso es el texto Putas y Guerrilleras, de Miriam Lewin y Olga Wornat, del año 2014.
} 
como productor de sentidos. A grandes rasgos se puede decir que luego de todas las críticas y deconstrucciones que sufrió la primera persona del singular, sobre todo en el Siglo XX, emerge nuevamente un yo como sujeto de enunciación habilitado. El resurgimiento de este yo dice relación con la oralidad y con la necesidad de registrar las vivencias de ciertos sucesos, sobre todo aquellos de la Segunda Guerra Mundial. En esta línea de análisis se encuentra Annette Wieviorka y su reflexión en torno a la Era del testigo (1998), quien indica incluso el carácter moralizador e irrefutable que ha adquirido el testimonio a partir de ciertos sucesos traumáticos y la necesidad que ha surgido de su registro.

Me interesa entonces, marcar un riesgo de carácter metodológico sobre el testimonio, y esto claramente sin caer en la desacreditación que promulga Beatriz Sarlo a este tipo de escritura. Es Fina Birulés quien amparándose en las palabras de Joan Scott, advierte sobre el peligro que implica la apelación a la experiencia personal como fundamento absoluto e incontestable de los análisis, ya que desde esta perspectiva se amputa toda posibilidad de crítica, y finalmente, de comprensión. Al respecto dice Scott: "La experiencia es, a la vez, siempre una interpretación y requiere una interpretación. Lo que cuenta como experiencia no es ni evidente ni claro y directo: está siempre en disputa, y por lo tanto siempre es político" (2001: 73).

Y esta re-interpretación está signada por su potencial crítico y constructivo, es decir, la experiencia personal es interpretada por otros, los otros que comparten el mundo común y que se constituyen como sujetos en él. En esta línea indica Birulés:

El discurso del testigo o del superviviente tiene, por supuesto, importantes efectos morales y políticos. Pero es importante distinguir entre la canonización de las víctimas y el potencial que tienen sus testimonios para lecturas críticas que permitan tanto escribir la historia a contrapelo como atender a la complejidad de acontecimientos terribles de nuestro tiempo; así como reparar en sujetos que hasta hace poco tiempo han sido minusvalorados, para quienes decir yo tiene un significado político al hacer emerger un sujeto imprevisto (Birulés, 2011: 17).

En efecto, son precisamente las voces de esos sujetos imprevistos y su potencial crítico lo que me interesa destacar, y en ningún caso poner en marcha un ejercicio de canonización, como indica Birulés, pues esto, desde mi perspectiva, desvirtuaría la riqueza de un análisis político, al menos en sentido arendtiano. De este modo, la narración testimonial operaría como una llave que permitiría acercarse desde una dimensión crítica a ciertos acontecimientos olvidados de la 'Historia', poniendo en evidencia la fragilidad discursiva y fáctica sobre la que se asienta el presente. En este sentido, y como hemos visto, la narración de la experiencia se encuentra en una particular relación con la memoria y la verdad. Aunque no entraré en este escrito particularmente en el tema de la verdad, me interesa mostrar que en vez de vislumbrar un régimen de veridicción científica en la narración testimonial, busco evidenciar su potencial 
Mariela Cecilia Ávila. La dimensión filosófica del testimonio...

práctico. Es decir, que en vez de intentar juzgar la veracidad de los discursos, me interesa ver que es lo que estos pueden generar: su régimen de acción, vale decir, sus efectos de sentido en nuestro presente.

\section{Testimoniar los campos de concentración. La apertura a nuevos efectos de sentido}

En la investigación postdoctoral que desarrollo actualmente, uno de los ejes de análisis dice relación con el carácter productivo y antiutilitario de los campos de concentración, problema que abordo desde la obra de Hannah Arendt. Si bien considero que gran parte del trabajo de Arendt sobre el totalitarismo permite iluminar otros sucesos afincados en el terror, creo que su reflexión sobre la productividad de los Lager nazis no sería suficiente para abarcar el análisis de los centros clandestinos de detención de las últimas dictaduras del Cono Sur, y esto debido a ciertas diferencias constitutivas.

Si bien, tal como indica Pilar Calveiro, el campo de concentración es un dispositivo que se alimenta a sí mismo para poder mantenerse en movimiento, situación a la que apunta también Arendt respecto a los Lager nazis, considero que esta dimensión podría ampliarse a partir de lo que he dado en llamar una productividad hacia afuera, que sobrepasa el espacio de excepción de estos dispositivos, y genera ciertos efectos en el espacio al que se circunscribe.

En efecto, esta productividad hacia afuera tiene diversas materializaciones, entre las que destacan fuertemente ciertas formas de subjetivación a partir de la escritura, es decir, ciertas narraciones que adquieren la forma de testimonios. Nos encontramos así frente a una discursividad sobre el terror y sus consecuencias, sobre la búsqueda de aniquilación de la humanidad, pero también sobre las diversas formas de supervivencia y resistencia que pueden encarnar los sujetos en estos contextos de encierro. Creo entonces que el testimonio como narración acontecimental, se ha convertido en el mayor registro productivo de los campos de concentración, en esa productividad hacia afuera que trasciende fronteras físicas y simbólicas y que de alguna manera, interpela una reflexión desde lo comunitario sobre el tejido social y su organización.

En este sentido, es interesante notar que aunque algunos de los testimonios fueron escritos y publicados durante el proceso dictatorial, sobre todo desde el exilio, la mayoría pertenecen al periodo post-dictatorial y transicional. Es decidor que la narrativa testimonial siga creciendo y aumentando en la actualidad, pues año a año se publican numerosos testimonios que abordan el problema dictatorial desde diversas perspectivas. Así, esta forma de productividad con su potencial crítico y develador de sentidos, lejos de agotarse sigue creciendo y presentando nuevas perspectivas analíticas y críticas. Cristina Feijóo en el prólogo del testimonio de Graciela Lo Prete, publicado más de veinte años después de su muerte, alude a la expansión incontenible que tienen las narraciones testimoniales de la siguiente manera: "Son

libros que transfunden boca a boca un aliento y un ritmo sin igual, movimientos del espíritu cuyas ondas se extienden infinitamente, como si el acto de escritura no cesara jamás" (Dillet, 2006: 11). 
Parto entonces de esos actos de escritura cuyos efectos parecen no cesar, a fin de esbozar ciertas reflexiones sobre los campos de concentración y su relación con el testimonio. Se trata de reflexionar sobre el modo en que los individuos toman la palabra para narrar la violencia y el terror experienciados al interior de estos espacios, recubiertos por una excepcionalidad imperante, tanto en el plano jurídico, como en legal y subjetivo. Dicha excepcionalidad sentaba la prerrogativa del poder de desaparición sobre los cuerpos de los secuestrados. En efecto, un poder desaparecedor e institucionalizado posibilitaba el secuestro y la detención clandestina de aquellos individuos que representaban una amenaza para los planes de las Juntas Militares de los países del Cono Sur ${ }^{7}$.

En este contexto, los presos que habitaban los campos de concentración no sólo habían desaparecido para los que quedaban afuera, sino que debían afrontar un complejo camino, en el que se buscaba incurrir en su propio vaciamiento, al que Pilar Calveiro caracteriza con las siguientes palabras: “(...) personas vivientes que ya habían desaparecido del mundo de los vivos y ahora desparecerían desde dentro de sí mismos en un proceso de "vaciamiento" que pretendía no dejar la menor huella." (Calveiro, 2008: 47) Hacer desaparecer del afuera, pero también del adentro, tal era el cometido de las Juntas Militares, lograr que los disidentes políticos no sólo dejaran de lado sus ideas y formas de vida, sino que fueran reformateados, hasta convertirse en otros diversos de sí mismos, y de ese modo poder reintegrarlos en la sociedad, en su carácter de "recuperados". Se buscó aniquilar aquellas subjetividades que se contraponían al corpus de valores y modos de vida implementados por el poder militar. En este sentido, Munú Actis en diálogo con sus ex compañeras de presidio dice: "Me pregunto entonces cómo vivíamos esa circunstancia, qué sentíamos al mirar por la ventana del comedor de arriba y saber que los que estaban afuera creían que no existíamos" (Actis y otras, 2001: 85).

El proceso de desaparición del afuera -pero también del adentro- comenzaba con la anulación del nombre propio, con la aniquilación del yo a partir de la supresión del nombre y apellido del preso. Este es un elemento que aparece de forma recurrente en las narraciones testimoniales, pues parece ser una de las primeras situaciones que sufren los secuestrados, que en algunos casos es considerado algo terrible, mientras que en otros, no cobra tal sentido, sin embargo, en todas las narraciones pareciera operar como un punto de inflexión dentro del encierro. Nora Strejilevich, en su texto Una sola muerte numerosa lo narra de la siguiente manera: "Cuando me robaron el nombre fui una fui cien fui miles y no fui nadie. NN era mi rostro despojado de gesto de mirada de vocal” (Strejilevich, 2006: 13). Mediante la técnica de supresión del nombre propio se buscó borrar la subjetividad de los secuestrados, sumirlos bajo un manto de olvido que implicaba también el olvido de sí mismos.

\footnotetext{
${ }^{7}$ Esta problemática ha sido abordada por mí en otros artículos, para profundizar sobre ella, Cfr.: Avila, Mariela (2013a y 2013b).
} 
Mariela Cecilia Ávila. La dimensión filosófica del testimonio...

Y en esta línea va precisamente el último punto que quiero abordar en este escrito, el de la subjetividad, una subjetividad que con Jaume Peris Blanes llamamos mutilada (Peris Blanes, 2005: 69), cuya reconstitución, o rehabilitación, creemos, tiene que ver en gran medida, precisamente, con la posibilidad de testimoniar. En este sentido Peris Blanes indica:

Los testigos testimoniaron, por tanto, de los restos del sujeto, ya que daban cuenta de aquello que quedaba de lo humano tras el proceso de aniquilación subjetiva que tiene lugar en la tortura.

Pero además, el testimonio refutaba en cierta forma esa aniquilación construyendo un sujeto capaz de narrarla (Peris Blanes, 2008: 75).

La re-construcción de la subjetividad, en muchos casos, estuvo signada precisamente por la posibilidad de testimoniar que se imponían los testigos. Tal como hemos indicado, según Hannah Arendt, la narración pone un "quien" en el devenir temporal, pues esta 'Historia', la de las grandes narraciones, se constituye de pequeñas storys, a las que podemos pensar también bajo la forma del testimonio. En nuestro análisis situado, es posible observar el modo en que la narración de ciertas experiencias del horror irrumpen para mostrar las grietas y oscuridades de aquellos discursos normativos que pretenden explicar un tiempo, pero sobre todo, para poner en evidencia que incluso aquellas subjetividades quebradas por la tortura y el dolor pueden resistir, re-armarse y reconstituirse a través de la narración.

Las narraciones testimoniales, además de poner en escenas subjetividades muestran también otras formas de abordar los fenómenos, de hecho, considero que la vía primordial de acercamiento a los campos de concentración del Cono Sur, ha estado dada por la narración de los testigos. En efecto, tal como indica Peris Blanes, el acercamiento entre un tiempo actual y la temporalidad del campo nos es dado a partir de las palabras del testigo (Peris Blanes, 2005: 69). Sólo a partir de su narración podemos asomarnos a aquellos sucesos experienciales que la reflexión historiográfica no alcanza a completar.

Quizá el caso más paradigmático de este acercamiento sea el texto Tejas Verdes, de Hernán Valdés, escrito algunos meses después de abandonar el campo de concentración y publicado por primera vez en Barcelona en el año 1974. Sin embargo, son numerosos los escritos que han aparecido -y continúan apareciendo-, que narran la estadía de los presos políticos en los centros clandestinos de detención, donde el intento por aniquilar la subjetividad y todo atisbo de resistencia parece ser uno de los elementos centrales de estas narraciones.

Aparece así la voz de una subjetividad mutilada, que posibilita un análisis que triza universos discursivos, permitiendo una mirada crítica para pensar y repensar el lugar de la experiencia en nuestro presente. Sin embargo, en esta línea, considero fundamental tener en cuenta la crítica de Benjamin a la noción de experiencia, a partir de la cual no sería posible leer las narraciones como una justificación de los sucesos, sino que habría que comprenderlas como quiebres en la linealidad de la historia, pero 
también, y quizá sobre todo, como fisuras al interior del discurso mismo ${ }^{8}$, lo que nos obliga a repensarnos tanto a nivel individual como colectivo.

En este sentido, se vislumbre el potencial de pluralidad del testimonio, que si bien, como se ha indicado, en principio puede parecer una tarea singular, sus efectos dan pistas para pensar el mundo en común al rehabilitar sentidos para la comunidad. Es decir, las repercusiones de los testimonios dicen relación con nuestro hacer común en el espacio público, pues a partir de estas narraciones es posible construir y reconstruir críticamente desde una dimensión plural el presente. Y pienso en la noción de pluralidad desde una doble dimensión, pues aludo a la comunidad de seres plurales de la que habla Arendt, pero pienso también en Nietzsche (1983: 33) cuando dice que el cuerpo es una construcción social de muchas almas, porque creo que es precisamente esa pluralidad la que nos permite re-pensarnos, re-narrarnos y re-constituirnos más allá del horror.

\section{Conclusiones preliminares}

De esta manera, espero haber presentado una posible línea de análisis para pensar la relación entre la filosofía y el testimonio: una línea que permitiría reflexionar sobre el lugar de la experiencia y la vivencia al interior de una indagación filosófica situada. Si bien este trabajo se inserta en un proyecto mayor, el presente análisis responde a una necesidad metodológica e incluso epistemológica, que busca dar cuenta del estatuto del testimonio y su relación con una filosofía que se asienta en los acontecimientos de la historia.

Considero entonces que la figura del testimonio se constituye en una interesante clave de lectura que permite apreciar desde otra perspectiva ciertos sucesos, sobre todo aquellos de carácter traumático, afincados en la violencia dictatorial. La mirada de la experiencia se insertaría, cual daga, en la aparente linealidad histórica para trizarla, y hacer evidente las capas y superposiciones que constituyen los acontecimientos.

De este modo, mi aproximación al testimonio es absolutamente interesada, pues abre una puerta de conocimiento alternativa a los sucesos para escudriñarlos desde la singularidad que tiene la vivencia particular. Es la palabra del testigo la que ofrece una nueva clave analítica para los acontecimientos, con un lenguaje y un tiempo verbal que siempre se está reconstruyendo. Esta reconstitución permanente es la que da cuenta, a su vez, de la narración como un posible modo de subjetivación. Si bien el punto de

\footnotetext{
${ }^{8}$ Todo ello aun considerando la dificultad a la que alude Benjamin sobre la puesta en entredicho de la experiencia, y la posibilidad de quedar anclados a la mera vivencia en su texto El narrador (2008). Mi interés reside, entonces, en vislumbrar una posible relación entre la experiencia, la comunidad y la tradición que mantiene dicha comunidad, que es lo que para Benjamin se ha visto quebrado con la Primera Guerra Mundial y la pérdida de las tradiciones y el mundo en común. Esta relación podría verse reflejada en la narración testimonial, como forma "artesanal" de transmisión, y su incidencia en el mundo común.
} 
inicio de esta investigación son los campos de concentración, las palabras que brotan de los testimonios permiten ampliar el espectro de análisis y proyectar una mirada más vasta sobre los sucesos y los sujetos que quedan implicados en esta trama histórico-política. Es por ello que considero la escritura testimonial como la mayor fuente de producción de los campos de concentración, una producción hacia a fuera, que arrasa con las barreras físicas, temporales y discursivas, para poner en evidencia sucesos que a la vez que constituyen y explican el presente, nos construyen como sujetos políticos.

Concuerdo con Pilar Calveiro cuando indica que los campos de concentración son los dispositivos institucionales que reordenaron el tejido social durante la dictadura, y me pregunto si la perpetuación de algunas de sus prácticas, pero sobre todo la dimensión narrativa que han desencadenado, no continuaría reorganizándolo de alguna manera, aún en el presente. Seguramente esto requiere un mayor análisis, pero la idea agambeniana (2006) de ampliación de la excepcionalidad jurídica y de la trascendencia espacial y temporal del campo de concentración a través de la categoría de paradigma, puede darnos pistas para pensar este problema. Además, los efectos de sentido que han desencadenado las palabras de los testigos de estos sucesos, parecen haber impuesto una suerte de imperativo social, que imposibilita el desoír las voces de los narradores de estos sucesos anclados en la violencia y el peligro.

Así, sería posible ver junto a Benjamin que "Articular históricamente lo pasado no significa 'conocerlo como verdaderamente ha sido'. Consiste, más bien, en adueñarse de un recuerdo tal y como brilla en el instante de un peligro" (Reyes Mate, 2009: 113). Ese instante de peligro nos advertirá sobre las metamorfosis de ciertos sucesos, que tienden a perpetuarse bajo distintas pieles. Por ello considero que la narración, en tanto una forma de adueñarse de un recuerdo, puede operar también como una advertencia de lo sido, que no necesariamente debe continuar siendo. Podemos pensar entonces, que el testimonio es la experiencia arrancada al pasado, puesta en el presente y arrojada al futuro, pues como indica Arendt, nunca terminaremos de conocer sus consecuencias ni las posibilidades que abre en quien enuncia y en quien recibe. En este sentido, vislumbramos incluso una dimensión utópica en el testimonio, pues su imposible clausura da cuenta de un futuro abierto, nunca circular y siempre a disposición de la acción de los hombres. 
Mariela Cecilia Ávila. La dimensión filosófica del testimonio...

\section{Bibliografía}

Actis, Munú, Aldini, Cristina, y Otras (2001). Ese infierno. Conversaciones de cinco mujeres sobrevivientes de la ESMA. Buenos Aires: Editorial Sudamericana.

Agamben, Giorgio (2006). Homo sacer. El poder soberano y la nuda vida. Valencia: Pre-textos.

Arendt, Hannah (2008). La condición humana. Buenos Aires: Paidós.

Arendt, Hannah (1953). Comprensión y política. Las dificultades de la comprensión. Traducción: Cristina Sánchez Muñoz. Barcelona: Biblioteca Libre.

Arendt, Hannah (2005). Essays in Understanding 1930-1954. New York: Schocken Books.

Avila, Mariela. "Estados de excepción y campos de concentración en Chile. Una aproximación biopolítica”. Revista Sociedad Hoy (2013): 65-78.

Avila, Mariela. "Campos de concentración de las dictaduras latinoamericanas. Una mirada filosófica". Revista La Cañada 5 (2013): 215-231.

Benjamin, Walter (1996). La dialéctica en suspenso. Fragmentos sobre la historia. Traducción Pablo Oyarzún. Santiago: Lom- Universidad Arcis.

Benjamin, Walter (2008). Elnarrador. Traducción Pablo Oyarzún. Santiago: Metales pesados.

Beverley, John. "Subalternidad y testimonio". Nueva Sociedad 238 (2012): 102-113.

Birulés, Fina (2011). "Entre el descrédito y la rehabilitación del yo". Las personas del verbo (filosófico). (Manuel Cruz, ed.). Barcelona: Herder.

Calveiro, Pilar (2008). Poder y desaparición. Los campos de concentración en Argentina. Buenos Aires: Colihue.

Dillet, María Graciela (2006). La Lopre. Memorias de una presa política. Buenos Aires: Norma.

Dosse, François (2003). La historia: conceptos y escritura. Buenos Aires: Nueva Visión.

Halwbachs, Maurice (2011). La memoria colectiva. Buenos Aires: Miño y Dávila.

Löwy, Michael (2012). Walter Benjamin: aviso de incendio. Una lectura de las tesis "Sobre el concepto de historia". Buenos Aires: Fondo de Cultura Económica.

Nietzsche, Friedrich (1983). Más allá del bien y del mal. Madrid: Alianza.

Peris Blanes, Jaume (2005). La imposible voz. Memoria y representación de los campos de concentración en Chile: la posición del testigo. Santiago: Cuarto Propio. 
Peris Blanes, Jaume (2008). Historia del testimonio chileno. De las estrategias de denuncia a las políticas de la memoria. Valencia: Universitat de València.

Pollak, Michel (2006). Memoria, olvido, silencio. La producción social de identidades frente a situaciones límite. La Plata: Al Margen.

Reyes Mate, Manuel (2009). Medianoche en la historia. Comentario a las Tesis de Walter Benjamin "Sobre el concepto de historia". Madrid: Trotta.

Sarlo, Beatriz (2013). Tiempo pasado. Cultura de la memoria y giro subjetivo. Una discusión. Talca: Universidad de Talca.

Scott, Joan. “Experiencia”. La Ventana 13 (2001): 42-73

Strejilevich, Nora (2007). Una sola muerte numerosa. Córdoba: Alción Editora.

Valdés, Hernán (2012). Tejas Verdes. Diario de un campo de concentración en Chile. Santiago: Taurus.

Wieviorka, Annette (1998). L'ère du témoin. Paris: Pluriel.

Wornat, Olga y Lewin, Miriam (2014). Putas y guerrilleras. Buenos Aires: Planeta. 